\title{
EL ESPACIO CONSTRUIDO, EL BANQUETE Y LA FIESTA EN DURMART LE GALOIS
}

\author{
Esperanza BERMEJo LARREA \\ ebermejo@unizar.es \\ Universidad de Zaragoza
}

\section{INTRODUCCIÓN}

Durmart le Galois ${ }^{1}$ (en adelante Durmart), compuesta hacia 1215-1220, muestra algunas peculiaridades con respecto a la tradición de la novela artúrica. Alberga cuatro prólogos. El primero (vv. 1-20) justifica, dentro de la tradición del exordium, la tarea del escritor y el fin didáctico de su obra, a la vez que presenta la historia cuyo protagonista es hijo de un rey. El segundo (vv. 567-571) recrea el topos primaveral de la reverdie: el invierno se acaba, el tiempo se suaviza, «Li boiz et li vergier florissent» (v. 569) y se escucha el canto de los pájaros en los campos. Se trata de la estrofa primaveral de la chanson courtoise que, asociada a las fiestas de Pascua, Ascensión o Pentecostés, sirve de inicio a numerosas narraciones ${ }^{2}$. Este prólogo relata el arrepentimiento de Durmart, el reconocimiento de su error y su decisión de ser investido caballero. La materia da un giro, la relación amorosa del héroe epónimo con la mujer del senescal finaliza y comienza una nueva vida en Pascua, coincidiendo con la estancia del rey Jozefent en la Blanche Cité. El tercer prólogo (vv. 921-926) repite el motivo del inicio primaveral, con ligeras variaciones. Esta vez se trata de Pentecostés, en el mes de mayo, y se incide en la belleza de la luz y especialmente de las flores: «Li rosiers florist et li glais» (v. 923), «La flors de lis naist et blanchoie» (v. 925). La

\footnotetext{
* Este trabajo se encuadra dentro de las actividades del grupo de investigación H58-ANESNAF del Gobierno de Aragón y del proyecto FFI2012-33895 del Ministerio de Economía y Competitividad.

${ }^{1}$ Todas las citas remiten a la edición de Durmart le Galois. Roman arthurien du treizième siècle, ed. de Joseph Gildea, 2 vols., Villanova (Penn.), The Villanova Press, 1965-1966.

${ }^{2}$ Roger Dragonetti, La technique poétique des trouvères dans la chanson courtoise: Contribution à l'étude de la rhétorique médiévale, Ginebra, Slatkine Reprints, 1979, pp. 163-176, examina el motivo del paisaje y de las estaciones, inicio frecuente de la canción cortés, desde la tradición de la poesía medio-latina y la retórica medieval hasta la poesía lírica, cantares de gesta y novelas medievales. Philippe Walter, La mémoire du temps. Fêtes et calendriers de Chrétien de Troyes à La Mort Artu, París, Librairie Honoré Champion, 1989, pp. 201-222, analiza la función de las fiestas del calendario litúrgico en el relato de tipo curial de la novela cortés. Emmanuèle Baumgartner, Chrétien de Troyes. Yvain, Lancelot, la charrette et le lion, París, Presses Universitaires de France, 1992, pp. 39-40, estudia la cronología de las novelas que componen su título, a partir de la elección de la fiesta litúrgica que abre cada relato.
} 
investidura caballeresca de Durmart se lleva a cabo en la corte plenaria, reunida en la Blanche Cité con ocasión de la fiesta litúrgica. La letrina del copista en el único manuscrito conservado resalta el verdadero comienzo de la aventura del protagonista: «Par un matin souz chevaçoit» (v. 1575), momento en el que Durmart encuentra un caballero cuyo lebrel le conducirá hasta la reina de Irlanda, aunque ésta vaya de incógnito. El discurso del narrador subraya el inicio del relato: «Or primes commence li contes» (v. 1574).

La estructura de la novela se organiza en tres partes de alcance desigual. La primera relata la recreantise y la falta de Durmart, enamorado de la mujer del senescal. A diferencia de la de Erec, en Erec et Enide de Chrétien de Troyes (cuya ociosidad representa la crisis social del caballero y organiza la conjointure de la novela), en Durmart esta etapa se cierra sobre sí misma, sin guardar ningún lazo con el resto del relato. Constituye, más bien, una especie de preludio narrativo a la verdadera aventura del héroe, la búsqueda de la reina de Irlanda, que centra la segunda parte de la historia. El motivo artúrico del "Arbre aux chandelles", mencionado al comienzo de la aventura de Durmart, reaparece para desencadenar la tercera y última parte. El narrador refiere brevemente la peregrinación-cruzada de los esposos a Roma, ciudad que liberan del asedio de cuatros reyes sarracenos y en la cual el Papa explica a Durmart la significación escatológica del árbol ${ }^{3}$.

La conjointure de esta novela no presenta, a diferencia de otros textos artúricos, una etapa de crisis personal o social del héroe que $^{4}$ impulse la acción hacia su progreso psicológico o moral. Sin embargo, la aventura se ordena con arreglo a una disposición ternaria que recurre a los procedimientos de la repetitio y de la simetría. Las dos estancias del héroe en el castillo de Brun de Branlant, precedidas ambas de su extravío, enmarcan la parte central de la búsqueda, en la que se encadenan los episodios de los castillos y del torneo de Blanches Mores. La primera, que ha perdido su función iniciática, culmina con el episodio del gavilán, cuyas consecuencias se extienden por toda la novela. La tercera consagra la gloria del héroe tras la guerra de Limeri. De la prueba individual a la colectiva: la gradatio guía la aventura caballeresca de Durmart.

La geografía de Durmart es muy extensa, tanto como la novela que se despliega a lo largo de dieciséis mil versos. Las aventuras del protagonista se desarrollan en tierras de Gales, Logres, Northumbria, Irlanda, Roma y Dinamarca. En este inmenso espacio, los castillos

\footnotetext{
${ }^{3}$ Según Antoinette Saly, «L'arbre illuminé et l'arbre à l'enfant», Senefiance. Image, Structure et Sens. Études arthuriennes, 34 (1994), pp. 171-186, este motivo, separado del Grial en Durmart, sintetiza dos tradiciones: la folklórica del árbol iluminado y la iconográfica cristiana del árbol con el niño que trepa.

${ }^{4}$ Marie-José Southworth, Étude comparée de quatre romans médiévaux. Jaufre, Fergus, Durmart, Blancandin, París, Librairie A. G. Nizet, 1973, p. 108.
} 
y las ciudades se humanizan y se yerguen como espacios privilegiados de la aventura, frente a otros lugares no construidos y salvajes, como el bosque o la landa habituales en las novelas artúricas. Por otra parte, la recurrencia de escenas de ágapes evocadas en la novela (se cuentan veintisiete), cuya descripción se presta a variaciones significativas en función del marco en el que se celebra -fiesta cortés, al aire libre, o incluso acompasando la guerra contra el rey Nogantrefuerzan la importancia que la sociabilidad y la convivialidad entre los personajes adquieren en esta novela. Durmart ilustra un ideal de vida, en el que el ceremonial y la largueza conviven con las proezas caballerescas.

El objetivo de este trabajo es mostrar cómo Durmart se aleja de los motivos de la tradición artúrica, en un claro ejercicio desmitificador. Se articula en torno a dos apartados, que analizan la convivencia en la novela de dos modelos de descripción de ciudades y de castillos. Frente al modelo establecido por la tradición novelesca, que privilegia el aislamiento para asegurar la defensa de sus habitantes en la guerra, Durmart desarrolla uno nuevo, compuesto por castillos y ciudades abiertos más allá de sus murallas, en los cuales se celebran fiestas, torneos o banquetes y se exhibe un modo de vida más placentero y cortesano. Estas ciudades nuevas, Blanche Cité y Limeri, desplazan a las sedes tradicionales de la corte artúrica de sus funciones habituales.

\section{Dos MODELOS DE CIUDAD}

Ocho ciudades se distribuyen de forma diversa el espacio narrativo de Durmart. El autor alterna nombres tradicionales de las novelas artúricas, como Carduel y Glastingebiere (Glastonbury), con topónimos anclados en una geografía auténtica como Limeri (identificada con Limerick en Irlanda), Bangort (Bangor, Gales) y Roma, pero también inserta otros imaginados: la Blanche Cité en el país de Gales, residencia del rey Jozefent y de su mujer la reina Andelise; Blanches Mores, escenario del torneo y Landoc, lugar de la aventura del gavilán. Si se exceptúan Bangort y Carduel, cuya presencia ocasional resulta completamente secundaria ${ }^{5}$ y Roma, donde se desarrolla la última proeza de Durmart, la descripción de las ciudades repite un procedimiento similar, que consiste en fragmentar la información e integrarla en el discurso del narrador o del personaje, en función de la perspectiva elegida. El modelo de descripción en bloque, establecido por las novelas antiguas y por $\mathrm{Wace}^{6}$, es sustituido por una descrip-

\footnotetext{
${ }^{5}$ Bangort v. 5064 y v. 15881; Carduel v. 8499 y 12713.

${ }^{6}$ Según G. D. West, «The Description of Towns in Old French Verse Romances», French Studies, 11 (1957), pp. 50-59, las ciudades de Karlion y sus alrededores en la novela Brut de Wace y Cartago con sus murallas y mercado en Eneas constituyen los modelos imitados por los novelistas posteriores. Para Marie Françoise Notz, «La ville a-t-elle une image au
} 
ción fragmentaria, a veces esquemática, que se funde de forma más natural con la intriga y crea un efecto de realismo o de verosimilitud. La técnica no es exclusiva de esta obra, pues aparece también en las llamadas novelas realistas, de Jean Renart a Philippe de Beaumanoir, cuyas fechas de composición ${ }^{7}$ se aproximan a la de Durmart.

La Blanche Cité ocupa un lugar predominante en la novela. Es el punto de partida de la aventura de Durmart y confirma, al final, la apoteosis del héroe tras su boda en Limeri. Asume las funciones tradicionales de la corte del rey Arturo en las novelas $\operatorname{corteses}^{8}$, le arrebata su brillo y la relega a un segundo plano9. La mayoría de las referencias a la ciudad (siete sobre ocho) se localizan en los mil primeros versos, coincidiendo con los tres prólogos que lanzan la intriga. Se caracterizan por su brevedad, oscilando entre uno y siete versos, salvo la última que cuenta trece.

La primera referencia a la Blanche Cité se limita a la casa del senescal, cuya mujer mantiene una relación amorosa con Durmart durante tres años. Su descripción utiliza la enumeración de substantivos con polisíndeton, acompañados de adjetivos que subrayan su riqueza y aislamiento conforme al canon tradicional:

Mout i avoit riche maison,

Palaiz et sale et halt doignon;

Li manoirs estoit bien fermés

De halz murs et de grans fossés. (vv. 153-156)

Moyen Âge?», Eidôlon, 32 (1987), pp. 53-73; pp. 62-63, la imagen de la ciudad se define por su diversidad seductora, mientras que la del castillo «s'organise autour d'un centre où réside la manifestation visible d'un principe souverain». Paul Zumthor, «L'espace de la cité dans l'imaginaire médiéval», en Rosanna Brusegan (ed.), Un'idea di città. L'imaginaire de la ville médiévale, Milán, Arnoldo Mondadori Editori, 1992, pp. 17-26; p. 22, identifica tres elementos que conforman el arquetipo de la ciudad imaginaria medieval: clausura, por lo tanto, aislamiento; solidez, es decir, seguridad y verticalidad. La descripción de las ciudades en las novelas antiguas muestra, según Catherine Croizy-Naquet, Thèbes, Troie et Carthage: poétique de la ville dans le roman antique au XII siècle, París, Honoré Champion, 1994, un trazado descriptivo que avanza del exterior al interior, al que se añade la riqueza como rasgo distintivo. Se puede consultar también Philippe Ménard, «La ville dans les romans de chevalerie en France aux XII et XIII ${ }^{e}$ siècles», en Rosanna Brusegan (ed.), Un'idea di città. L'imaginaire de la ville médiévale, Milán, Arnoldo Mondadori Editori, col. Supplementtto Nuovi Argomenti, 1992, pp. 96-109.

${ }^{7}$ La composición de Durmart hacia 1215-1220 coincide con la de algunas novelas denominadas realistas: L'Escoufle y Guillaume de Dole de Jean Renart, 1200 y 1210 respectivamente; Galeran de Bretagne posterior a 1215; Le roman de la Violette de Gerbert de Montreuil entre 1220-1240; Jehan et Blonde de Philippe de Beaumanoir anterior a 1240.

${ }^{8}$ Durmart exige a los caballeros vencidos en buena lid (Caballero del lebrel, Brun de Morois, Felón de la Garde, Creoréas) que se presenten ante su madre, la reina Andelise; ante el rey Arturo a Brun de Morois, raptor de la reina Ginebra, y a Creoréas, carcelero de mil prisioneros.

${ }^{9}$ Friedrich Wolfzettel, «Idéologie chevaleresque et conception féodale dans Durmart le Galois: l'altération du schéma arthurien sous l'impact de la réalité politique du XIII' siècle», en Charles Foulon et al. (eds.), Actes du XIV Congrès International Arthurien, Rennes, 16-21 août 1984, Rennes, Presses universitaires de Rennes, 1985, pp. 668-686; p. 668. 
La perspectiva de la Blanche Cité cambia al mismo tiempo que muda la historia de Durmart. El héroe toma conciencia de su error y abandona a la mujer del senescal para ser investido caballero y poder demostrar su valía. La descripción de la ciudad, integrada ora en el discurso del narrador: «A la Blanche Cité en Gales | Todis avoit plaines ses sales | De chevaliers et de desduit» (vv. 573-575), ora en el del protagonista: «Li rois est en este cité | La sus en son palais pavé;» (vv. 623-624), se fragmenta en pinceladas que retienen cada vez un único elemento de su topografía: las salas, el palacio real y el mercado (v. 703). Mientras que los dos primeros espacios están asociados a la diversión de los caballeros, a pesar de la ausencia del hijo del rey Jozefent, en el mercado los burgueses lo censuran y desaprueban su comportamiento.

Los espacios antes diferenciados, salas, mercados y calles, se confunden con motivo de la corte plenaria de Pentecostés, bajo una alfombra de flores y de hierba fresca que evoca y amplifica el topos de la obertura primaveral (v. 921). Su descripción retórica reúne dos topoi: el del locus amœenus con sus elementos constitutivos ${ }^{10}$, los «arbres» (v. 999), los «oisel» (v. 1003), las «flors» (v. 1005), las «fontenelles» (v. 1007), y el de la reverdie: el «tens cler et bel» (v. 1004) y la renovación de la vegetación (vv. 1000 et 1005). La fiesta inunda la topografía de la ciudad y culmina en el banquete celebrado al aire libre en la pradera que se abre bajo las murallas, amenizado con música y canciones de amor, y seguido de juegos y divertimentos (vv. 996-1054). El festín, reforzado por el motivo de la tormenta (que anuncia siempre un cambio en la novela cortés ${ }^{11}$ ), desencadena la intriga.

El recorrido por la Blanche Cité, de la casa del senescal a la pradera, descubre un deslizamiento en la concepción del espacio, que va de la clausura y la protección a la abertura y a la diversión, del interior al exterior, al contrario de los itinerarios creados por los modelos descriptivos de las novelas antiguas. En esta primera parte de la novela, la fiesta rige la representación de la ciudad.

${ }^{10}$ Pierre Bühler, Présence, sentiment et rhétorique de la nature dans la littérature latine de la France médiévale de la fin de l'Antiquité au XIII siècle. Introduction à l'étude d'un mouvement esthétique, 2 vols., París, Honoré Champion, 1995, pp. 433-722, sintetiza, en su introducción al capítulo sobre el paisaje ideal, los elementos que integran el «locus amønus»: un bosquecillo sombreado, un arriate herboso, florido y oloroso; una fuente; un suave céfiro; el gorjeo de pájaros; el zumbido de las abejas; el canto de las cigarras y un clima primaveral.

${ }^{11}$ La súbita aparición de una tormenta constituye un fecundo recurso narrativo, pues introduce una ruptura en el relato para relanzarlo después. Ver J. H. Grisward, «À propos du thème descriptif de la tempête», en Mélanges de langue et de littérature du Moyen Âge et de la Renaissance offerts à Jean Frappier, Ginebra, Droz, 1970, pp. 375-389; Chantal ConnochieBourgne, «L'apaisement de la tempête dans la littérature médiévale: quelques exemples», en Francis Gingras (ed.), Une Étrange Constance: les motifs merveilleux dans les littératures française et francophone, Quebec, Presses de l’Université Laval, col. Symposium, 2006, pp. 107-120, y Danièle James-Raoul, «L'écriture de la tempête en mer dans la littérature de fiction, de pèlerinage et de voyage», Senefiance, 52 (2006), pp. 217-229. 
La recepción y la entrada solemne de Durmart y de la reina Fenise en la Blanche Cité superan la pompa de la coronación del héroe como rey de Irlanda en Limeri. Toda la población se moviliza y sale del recinto amurallado para dar la bienvenida a los recién casados, escoltados por el rey Jozefent. Se forma un cortejo en el que se mezclan sin distinción pobres y ricos (vv. 15312-15313), altos dignatarios de la iglesia, «hauz evesques» y «hauz abés» (v. 15323), poderosos barones (v. 15324) con damas y doncellas (vv. 15318-15319). La entrada real en la ciudad difumina las diferencias entre los ordines de la sociedad y los burgueses justan codo a codo con los caballeros: «La behordent sor grans chevas | Maint chevalier et maint borjois;» (vv. 15392-15393). La ciudad se engalana con hojas verdes y ramas (vv. 15389-15390) y muestra su opulencia con cortinas de púrpura y de seda colgadas sobre las calles (v. 15391). El sonido de las campanas hace vibrar la ciudad al son de la fiesta ${ }^{12}$.

La descripción de las ciudades de Landoc y de Blanches Mores también está asociada a la fiesta, expresada en ambos casos mediante los motivos de la multitud congregada (vv. 2317-2318 y vv. 6744-6745) y de la música. En Landoc se celebra anualmente la prueba del gavilán: «Quar chascun an i a grant feste» (v. 2010), definida por su carácter lúdico. Las doncellas «chantoient» (v. 2334), los caballeros y las damas «caroloient» (v. 2336), y otros se solazan con juegos variados (v. 2337). El torneo de Blanches Mores evoca más bien una atmósfera caballeresca, sugerida por las banderas que ondean al viento y el fulgor de las armas de los participantes (vv. 6752-6753). Una rica enumeración de instrumentos musicales, que armonizan timbres graves y agudos, convierte este ritual guerrero en un juego festivo:
Iluec flahutent et vïelent
Cil qui de ce sevent servir
Por les chevaliers resbaudir.
Li plusor servent de harper
Et li alquant de flajoler;

${ }^{12}$ El motivo de la entrada real en una ciudad, de frecuente aparición en las novelas realistas, contiene tres elementos principales: el cortejo que acompaña al personaje principal, que utiliza una montura; la muchedumbre y el movimiento en dirección a la ciudad. Suelen aparecer asociados a otros como la alfombra de flores o de hierbas (la jonchee), los adornos de la ciudad (incensarios, estandartes, telas colgadas sobre las calles) la música y el son de las campanas. En L'Escoufle, se suceden dos entradas de Guillaume y Aélis, la primera en Rouen (vv. 8240-8313), la segunda en Roma (vv. 8830-8864); cfr. Jean Renart, L'Escoufle. Roman d'aventure, ed. de Franklin Sweetser, París-Ginebra, Librairie Droz, 1974. La entrada de Liénor en Mayence, en Le Roman de la rose, tiene lugar el primer día de mayo; la alegría de la fiesta contrasta con la tristeza de la heroína, que debe demostrar su inocencia en la corte; cfr. Jean Renart, Le Roman de la rose ou de Guillaume de Dole, ed. de Félix Lecoy, París, Honoré Champion, 1969, vv. 4155-4194. La ciudad de Dammartin se engalana para recibir al conde de Oxford, padre de Blonde, al rey y a la reina en Philippe de Rémi, Jehan et Blonde, ed. de Sylvie Lécuyer, París, Honoré Champion, 1984, vv. 5640-5859. 


\section{Li auquant vont d'armes parlant, Et cil az tymbres vont tymbrant. (vv. 6754-6760)}

El banquete, ligado íntimamente a la fiesta cortés, como subraya Walter, significa «le luxe, l'abondance et le gaspillage et se relie à l'impératif de largesse $\rangle^{13}$. Tres banquetes acompasan los dos días de duración del torneo. Los dos primeros tienen un carácter universal, como la fiesta; el tercero, reservado al héroe y a sus diez compañeros, degustado en la mañana del combate, se caracteriza por la frugalidad requerida antes de la liza ${ }^{14}$ : «Poucins ont tenres, bien lardés | A vert jus qui de roisin fu» (vv. 8278-8279).

La distribución de los caballeros en los dos bandos del torneo no es gratuita, pues sintetiza las aventuras realizadas por Durmart. Su grupo de Blanches Mores se nutre, entre otros caballeros notables, de los vencidos por el héroe epónimo -el Felón de la Garde, Brun de Morois- y Geogenant, el caballero perfecto del Château aux Dix Pucelles. Los caballeros de la Mesa Redonda forman el otro grupo, el de Roche Lande. El torneo teatraliza el triunfo de Durmart sobre los legendarios caballeros artúricos, que será sancionado por las doncellas instaladas sobre la bella galería de la plaza, desde donde contemplan la proeza del héroe:

En milieu de la place droit

Avoit une loge de fust,

La plus bele qui onques fust.

N'ert pas mains haute d'une tor;

Trois cens fenestres ot entor.

La fisent cele loge faire

Deus puceles de haut afaire (vv. 6844-6850)

Glastingebiere ocupa una posición intermedia en la aventura de Durmart, entre el torneo de Blanches Mores y la guerra contra el rey Nogant. El héroe se dirige hacia allí, aprovechando la reunión plenaria de la corte en Navidad, en busca de información que le guíe hasta la reina de Irlanda, tras un largo extravío de cuatro meses. Su descripción, focalizada desde la perspectiva de Durmart, acompaña el recorrido de entrada del caballero a la ciudad, que no repara más que en dos únicos elementos del paisaje: el castillo y el palacio, caracterizados por los adjetivos formularios «grant», «riche» $\mathrm{y}$ «bel» (vv. 9383-9384). Sobre esta tela de fondo convencional, las ventanas

${ }^{13}$ Philippe Walter, La mémoire du temps..., op. cit., p. 452.

${ }^{14}$ El narrador no detalla los platos de la comida celebrada la víspera del torneo de SaintTrond en el Roman de la rose de Jean Renart (vv. 2446-2449), pero cuenta que los cocineros y los coperos sirvieron la carne y el vino que convenían a un torneo; añade que se comió poco. Sin embargo, en la comida anterior al torneo de Gligois se sirvieron capones, gallinas, aves de cría, pescado, pan y vino; cfr. Le roman de Gliglois, ed. de Marie-Luce Chênerie, París, Honoré Champion, 2003, vv. 2174-2194. 
lucen un elemento insólito que singulariza el edificio: «Deus cens escus qui i pendoient | Et trestot arengié estoient» (vv. 9387-9388). La exhibición de los escudos y su número significativo presagia la aventura que, según explica Sagremor le Desreé a Durmart (v. 9475), se revela como la gran prueba que un caballero podría afrontar durante la corte plenaria y está reservada, además, al protagonista, pues Cladain le Vert, irrumpiendo en la sala mientras se sirven los últimos platos del banquete, le desafía derribando su escudo. Este caballero venido de la Pequeña Bretaña es «... mout preuz | Et sages et chevalereuz; | Mout est jolis et envoisiés | Et larges et bien entechiés» (vv. 10279-10282); iguala las cualidades de Durmart, y el color verde de sus armas ${ }^{15}$ subraya su juventud, como la del héroe epónimo. El desenlace del combate se adivina incierto.

La aventura de los escudos enmarca la del "Siège Périlleux", objeto maravilloso, que, junto con el gran fuego de la chimenea, bastan para describir la decoración interior del palacio. Este asiento mágico hace perder la conciencia a quienes lo ocupan (vv. 9504-9508). El estrecho lazo que une el "Siège Périlleux" con el Grial en la trilogía de Robert de Boron desaparece en esta novela ${ }^{16}$. Ya no simboliza el asiento dejado vacante por Bron al lado de José de Arimatea, en la fundación de la mesa del Grial, que recuerda al de Judas durante la Última Cena ${ }^{17}$ y se asocia con la fundación de la Mesa Redonda ${ }^{18}$ en Merlin. En Didot-Perceval el asiento se convierte en una prueba que sanciona la excelencia caballeresca del «mieldres cevaliers del monde» ${ }^{19}$, y excluye al que se sienta en él sin merecer ese título, lo que le sucede a Perceval. Sin embargo, conserva su dimensión sagrada y desencadena un cataclismo semejante al que acompaña la muerte de Cristo: la piedra que soporta el "Siège" se raja y se hunde hasta el abismo, la tierra ruge en medio de las tinieblas y se desatan

${ }^{15}$ Michel Pastoureau, Figures et couleurs. Étude sur la symbolique et la sensibilité médiévales, París, Le Léopard d'Or, 1986, pp. 17, 30, afirma que «l'irruption dans le récit d'un chevalier inconnu aux armoiries plaines (monochromes) qui se dresse sur le chemin du héros et le défie, c'est toujours un événement à fonctionnalité retardée». El color de las armas es, en su opinión, un recurso del autor para sugerir lo que va a suceder. Así, «un chevalier vert est en général un jeune chevalier dont le comportement fougueux va être cause de désordre». En Durmart el color verde de las armas de Cladain le Vert subraya su juventud, idéntica a la del héroe al que se enfrenta, de reciente investidura.

${ }^{16}$ El "Siège Périlleux", el "Arbre aux chandelles" y el "Château des Pucelles" son los motivos ligados a la literatura del Grial que aparecen en esta novela. Para Francis Gingras, «Mise en recueil et typologie des genres aux XIII ${ }^{e}$ et XIV siècles: romans atypiques et recueils polygénériques (Biausdous, Cristal et Clarie, Durmart le Gallois et Mériadeuc)», en Olivier Collet y Yasmina Foehr-Janssens (eds.), Le recueil au Moyen Âge. Le Moyen Âge Central, Turnhout, Brepols, 2010, pp. 91-111; p. 110, Durmart ilustra una tendencia característica de la segunda mitad del siglo XIII, en el que los novelistas recortan e insertan en sus obras los motivos de la tradición novelesca modificando su sentido y cuestionando el modelo.

${ }^{17}$ Ver Robert de Boron, Le Roman du Graal Manuscrit de Modène par Robert de Boron, ed. de Bernard Cerquiglini, París, Union Générale d’Éditions, col. 10/18, 1981, p. 55.

${ }^{18}$ Ibid., p. 159

${ }^{19}$ Ibid., p. 204. 
todas las penas del mundo. El "Siège" está reservado a Galaz, que completa la búsqueda del Grial en La Queste del Saint Graal ${ }^{20}$. En Durmart este motivo se ha laicizado, ha perdido sus rasgos religiosos y derivado hacia la nigromancia, como ocurre con otros motivos artúricos. El "Siège Périlleux" enajena a los que en él se sientan:

El palais ot une chaiere;

Des ars estoit si conjuree

Et fu par nigremance ovree

Que poi de gent s'i asseïssent

Que tantost lor sens ne perdissent. (vv. 9504-9508)

Sin embargo, mantiene su función discriminadora y consagra al vencedor del castillo de Roche Lande y del torneo de Blanches Mores en la corte del rey Arturo, a la vez que ratifica el código cortés practicado en toda la novela, tanto por los adversarios como por los anfitriones de Durmart, y que alcanza su cénit en el Château aux Dix Pucelles:

En la chaiere nus ne siet

S'il n'est bons chevaliers eslis

Larges et loials et hardis

Et cortois et bien entechiés,

Qui tantost ne soit enragiés.

Avers ne trahitres ne faus

Ne parjures ne desloiaus

N'i puet seoir, c'est verités,

Que maintenant ne soit desvés. (vv. 9522-9530)

Ambos banquetes realzan la solemnidad de la víspera (vv. 97629818) y del día de Navidad (vv. 9912-9998). Su descripción pone de relieve la pompa y el refinamiento que rodea al ceremonial de la mesa. La suntuosidad de los vestidos de los asistentes, así como el número de filas en las que se distribuyen las mesas revelan la diferencia entre las comidas reales ${ }^{21}$ y las señoriales, entre la fiesta y lo cotidiano, pues el autor se muestra cicatero en los detalles sobre el lujo de la vajilla. Doscientas antorchas fijadas en los candelabros colgados del techo iluminan la sala; dos criados dan la señal con sendas trompetas de bronce para lavar las manos; los saleros son de

${ }^{20}$ Cfr. La Queste del Saint Graal. Roman du XIII siècle, ed. de Albert Pauphilet, $2^{\mathrm{a}}$ ed., París, Honoré Champion, 1980, pp. 4, 8-9.

${ }^{21}$ Martin Aurell, «Le roi mangeur et les élites à table», en Martin Aurell, Olivier Dumoulin y Françoise Thelamon (eds.), La sociabilité à table. Commensalité et convivialité à travers les âges. Actes du colloque de Rouen avec la participation de Jacques Le Goff, 14-17 novembre 1990, Rouen, Publications de l'Université de Rouen n 178, 1990, pp. 119-129, citando a J. Huizinga, afirma que a partir del siglo xv, bajo Carlos el Temerario, se produce un cambio en las comidas reales, que se convierten en magníficos espectáculos dramáticos. 
oro puro; Keu efectúa el servicio, asistido por quince caballeros de su mesnada en el primero y por cien donceles en el segundo (v. 9965); la música de arpas y vihuelas ameniza a los comensales. Durmart es honrado como exige su rango y su valor reconocido, y sentado junto al rey Arturo en el de la víspera y a Galván en el de Navidad. Ginebra, modificando su costumbre de comer en sus aposentos con sus damas ${ }^{22}$, asiste excepcionalmente al de Navidad para homenajear al caballero (vv. 9970-9972). Sin embargo, se observa una contradicción en las palabras del narrador sobre el protocolo, ya que en el banquete anterior la reina asiste al festín y se retira tan pronto como dejan de divertirle los entretenimientos posteriores ${ }^{23}$ (vv. 9816-9818).

La ciudad de Glastingebiere se asocia en Durmart a la prueba calificadora que confirma la integración del héroe en la Mesa Redonda. Sin embargo, su dureza está atenuada, pues la intervención del rey Arturo evita la muerte o la humillación del vencido, a la par que el significado del "Siège Périlleux" se banaliza. Por otra parte, el héroe declina el ofrecimiento del rey de permanecer en su corte y parte inmediatamente para proseguir su búsqueda. Así pues, la aventura personal de Durmart transcurre siempre lejos de la Mesa Redonda, emulando el quehacer del anónimo autor que se aparta de la significación canónica de los motivos artúricos incorporados en su novela.

La fiesta se adueña de Limeri con ocasión de la boda y coronación de Durmart (vv. 15048-1537). Esta ciudad fortaleza, asediada por el rey Nogant, como se verá más adelante, se transforma en un espacio lúdico que reúne múltiples manifestaciones de la fiesta cortés, desde las justas amistosas hasta el banquete y los bailes, todo adornado con la generosidad del héroe que distribuye dones y vestidos entre los caballeros y los ministriles. La investidura caballeresca de doscientos escuderos del Château des Moulins, llevada a cabo por Durmart y no por el rey Arturo, participante en los festejos, constituye su recompensa por haber liberado la ciudad, proclama su triunfo y erige a Limeri como rival de las ciudades artúricas, cuya hegemonía se difumina ante la proliferación de otros núcleos en los que brillan las luces de la cortesía.

La descripción y la función narrativa de la ciudad de Limeri resultan inseparables de las del Château des Moulins, del mismo modo que el encuentro de Durmart con el arquero César pone fin al errar solitario y a la búsqueda de la reina Fenise. Ambos lugares son el escenario de la guerra contra el rey Nogant, el episodio más largo de la novela (sus cuatro mil trescientos versos ocupan una cuarta parte

${ }^{22}$ En el banquete que celebra la coronación de Arturo, Wace cuenta que el rey y la reina comieron por separado: el rey con sus barones y la reina con sus damas, según la costumbre troyana conservada por los Bretones; cfr. Wace, Le roman de Brut, ed. de Ivor Arnold, 2 vols., París, Société des Anciens Textes Français, 1938, vv. 10446-10458.

${ }^{23}$ Esta contradicción en el protocolo apoya la tesis de Francis Gingras sobre esta novela compuesta a partir de fragmentos de novelas artúricas. Ver nota 16. 
del total) y donde finaliza la aventura del héroe. Limeri, asediada por el rey Nogant, es el último reducto de la reina de Irlanda, su prima y soberana, (vv. 10585-10587) en el centro de un país devastado. Es una ciudad refugio como la Jericó bíblica, lo que explica la primacía del aislamiento frente a los otros dos rasgos que integran, según Zumthor, el arquetipo de la descripción de la ciudad: la solidez y la verticalidad. Cuatro niveles de defensa aseguran su protección. En primer lugar, las murallas con matacanes, divisadas desde lejos por Durmart y César, aíslan la ciudad: «La cité de Limeri voient | Et les murs qui hordé estoient» (vv. 10809-10810), y cuya altura es subrayada por el arquero al aproximarse a ella: «Et ces haus murs que vos veés, |C'est la cités de Limeri» (vv. 10838-10839). Vienen detrás los profundos fosos (v. 10821) evocados por el narrador, pues escapan a la mirada de los caballeros. El emplazamiento del castillo sobre una roca (v. 10811), dominando la ciudad, acentúa su verticalidad y la hace inexpugnable. Los pantanos, que rodean Limeri junto con el río, triplican el grado de aislamiento e introducen al mismo tiempo un elemento topográfico característico de esta región irlandesa que renueva el canon tradicional:

Pöés bien ceas de l'ost choisir,

Mais ne püent a nos venir,

Car ves ci un mares trop grant

Et une riviere corant.

La riviere cort par dela,

Et li mares est par decha; (vv. 10868-10872)

Limeri se refuerza en su aislamiento, pues sus puertas están terraplenadas (v. 10976) y el único acceso es un portillo tan pequeño que es necesario agacharse para entrar (vv. 11022-11023). Replegada sobre sí misma, debe recurrir al Château des Moulins para organizar su estrategia de guerra.

La descripción del Château des Moulins presenta numerosas similitudes con la de la ciudad de Limeri. Su fisionomía representa una «forterece hordee» (v. 10885), alta y bien asentada (v. 10914), y cuenta también con tres niveles de protección dispuestos en círculos concéntricos. El primer anillo está formado por las construcciones defensivas: las altas murallas, los fosos profundos, el puente levadizo alzado (vv. 11105-11106) y las torres almenadas (v. 10920). Los pantanos y el río cercan casi por completo el castillo por segunda vez (vv. 10915-10916); un estrecho sendero los atraviesa, obstruido por cañizos (v. 11005) y tablas (v. 11006), por lo que resulta infranqueable a pie, a riesgo de caer en ciénagas y canteras de muelas (vv. 10992-10994). Finalmente, numerosos desvíos (v. 11095) dificultan la entrada de Durmart y de César al castillo. A pesar de su apariencia, la primera función de este castillo no es la guerrera (segunda función 
indo-europea), sino la alimenticia (tercera función), pues los diez molinos que encierra ${ }^{24}$ están destinados a asegurar el abastecimiento de los habitantes de Limeri durante el largo cerco impuesto por el rey Nogant: «Que ja le morre ne lairont | Por trestos ceas qui en l'ost sunt» (vv. 10907-10908). Aunque su descripción no conserva más que dos únicos vocablos específicos de su función primaria: «molans» (v.10893) y «molieres» (v. 10997), el rey Arturo se burla de su sobrino Galván designando a su adversario Procidas con el nombre de «molinero» ${ }^{25}$ y no de caballero:

Vos n'avés mie trop conquiz

Sor ceaz des molins, ce m'est viz.

Certes, il sunt bon chevalier,

Et si ont le millor mosnier

Qui gardaist molin onques mais; (vv. 13889-13893)

La ambivalencia funcional del Château des Moulins no es su único rasgo peculiar frente a los restantes castillos que jalonan la aventura de Durmart. No hay caballeros, pues su castellano Procidas, de casi dieciocho años de edad, tiene que esperar todavía uno para ser investido caballero, razón por la cual es designado como «vallés» (v. 10925), «danzeas» (v. 10926) o «chastelains» (v. 11666). Es el señor de cincuenta y nueve escuderos adiestrados en el arte de la guerra (vv. 10946-10953), y a su vez vasallo ligio de la reina Fenise. Este castillo es el señorío privilegiado de los jóvenes y espera la llegada de Durmart, reciente bacheler ${ }^{26}$, para lanzar la ofensiva contra el rey Nogant.

La topografía del Château des Moulins condiciona la estrategia de la guerra, que el relato desarrolla en dos fases de tres días ${ }^{27}$,

${ }^{24}$ La existencia de molinos de agua en Irlanda está documentada desde el siglo IX. Se dedicaban al abastecimiento de las poblaciones urbanas. Según Marc Bloch, «Avènement et conquête du moulin à eau», Annales d'histoire économique et sociale, 7 (1935), pp. 541-563; p. 552, la antigua estructura tribal de la sociedad irlandesa favoreció su expansión y administración colectiva.

${ }^{25}$ Los molinos y los molineros entran en la literatura medieval francesa, según Ménard, en el siglo XII. Su presencia en los textos medievales es escasa, dado que estos están destinados fundamentalmente a la clase aristocrática, a la que no interesan estos oficios. Aparecen en textos más próximos a la literatura cotidiana. Ménard, que no cita Durmart, recoge las siguientes referencias en novelas: Les Merveilles de Rigomer, primera mitad del siglo XII; Eustache le Moine, mediados del siglo XIII, Claris et Laris, último tercio del siglo XIII y Le Castelain de Couci et de la Dame de Fayel, finales del siglo XIII o comienzos del XIV; cfr. Philippe Ménard, «Moulins et meuniers dans la littérature médiévale», en Mireille Mousnier (ed.), Moulins et meuniers dans les campagnes européennes (IX $X^{e}-X V I I I^{e}$ siècle). Actes des XXI ${ }^{e s}$ Journées Internationales de l'Abbaye de Flaran, 3, 4, 5 septembre 1999, Toulouse, Presses Universitaires du Mirail, 2002, pp. 217-250; pp. 222-224.

${ }^{26}$ Sobre la noción de bacheler, ver Jean Flori, «Qu'est-ce qu'un bacheler? Étude historique de vocabulaire dans les chansons de geste du XII ${ }^{\mathrm{e}}$ siècle», Romania, 96 (1975), pp. 289-314.

${ }^{27}$ Aunque la guerra no dura más de un mes (v. 12692), el narrador sólo refiere con detalle dos series de tres días, separadas por la pausa de la llamada al rey Arturo. 
separadas por la pausa necesaria para justificar la llegada de los reyes Arturo y Jozefent, que se dirigen a Limeri en auxilio del rey Nogant. La naturaleza del lugar impide cualquier movimiento de los sitiadores, incluso el ataque por detrás contra los jóvenes del castillo, como asegura el prudente Procidas:

Nos n'avons garde de lor gent

Facent forclose ne cembel

Entre nos et nostre chastel,

Car li mares est trop parfons. (vv. 11634-11637)

Dada la inaccesibilidad del lugar, el único terreno posible para entablar combate es el que se extiende a lo largo del vado situado ante la ciudad de Limeri, lo que permite a sus habitantes asistir a las peripecias de la batalla como espectadores privilegiados. La guerra se convierte en un espectáculo, atenúa su ferocidad y se desliza sutilmente hacia la frivolidad del torneo, en la que Durmart se impondrá como vencedor absoluto:
Bien l'ont regardé et veü
Cil del Chastel de Limeri;
Chevalier et dame ausi
Sunt as cretealz et as toreles,
Et mout i a de damoiseles
Et de serjans et de borjois. (vv. 11771-11775)

La guerra feudal se transforma en cruzada travestida, como consecuencia de la falsa acusación de mécréantise lanzada por el rey Nogant contra la reina Fenise ${ }^{28}$. El pretendido carácter religioso del conflicto justifica la intervención del rey Arturo (vv. 14147-14150), y enfrenta, por segunda vez, a Durmart y a los caballeros de la Mesa Redonda. El desenlace de la guerra confirma la superioridad del hijo del rey de Gales sobre los caballeros artúricos.

La singularidad del Château des Moulins atañe también al ceremonial de las comidas que en él se celebran. Al contrario de lo que sucede con los banquetes igualadores de comensales, todos sus habitantes, excepto el capellán, comen en el suelo porque todavía no han sido investido caballeros:

${ }^{28}$ La reina Fenise, como mujer calumniada, debe defender su inocencia y su justificación se desarrolla conforme al procedimiento judicial medieval. La reina dispone de un valedor, el rey Jozefent y la defensa es pública. Utiliza tres tipos de argumentos, según la clasificación aristotélica: éticos que subrayan sus virtudes ante el público; patéticos destinados a obtener la adhesión a su causa, y la ordalía por fuego, que no tendrá lugar: «Et se li rois Artus, mes sire, | Ne me croit de ce qu'il m'ot dire, | Si face un grant fu alumer | Et beneïr et conjurer, | Et je irai parmi le fu» (vv. 14371-14375). El acusador se somete a un duelo judicial con Durmart, que tampoco tendrá lugar, pues el rey Nogant huye. 


\author{
A une table s'est assis \\ Mesires Durmars, s'i a pris \\ Un chapelain qui siet o lui; \\ Ensemble mangierent andui. \\ A la table n'en sisent plus, \\ Et li valet s'asisent jus, \\ Si mangierent par terre bas. (vv. 11277-11283)
}

La situación se repite en los días siguientes, pues el ritmo de los ágapes marca el paso del tiempo durante la guerra. El banquete excluye de la mesa a los que carecen de la condición caballeresca y establece una jerarquía vertical, de desigualdad, que la guerra contra el rey Nogant difumina temporalmente. Durmart propone adelantar la investidura de los escuderos como la única solución para compartir la alegría convival. De este modo, la novela rinde homenaje a los caballeros recientes, los bachelers, a través de la figura del héroe, de Procidas y de los jóvenes del Château des Moulins, quienes conseguirán juntos la victoria en la guerra de Limeri contra los consagrados caballeros de la Mesa Redonda.

\title{
2. De la Fortaleza al CAStillo deleitoso
}

Todos los castillos de esta novela excepto el de Moulins -Morois, de la Garde, Roche Brune y aux Dix Pucelles- se inscriben en la etapa central de la búsqueda de Durmart, marcada, como ya se ha dicho, por dos visitas del héroe al castillo de Brun de Branlant. En ellos acontecen algunas de las grandes hazañas del héroe - liberación de la reina Ginebra en el de Morois, de los cautivos en Roche Brune- o bien, sus castellanos proporcionan a Durmart informaciones valiosas para proseguir su aventura.

El castillo de Roche Brune representa para Durmart el camino más corto, pero también el más peligroso y por lo tanto debe evitarlo, según el consejo del ermitaño que le informa de la bifurcación que conduce a Glastingebiere, donde el héroe tendrá noticias de la reina de Irlanda. Su descripción evoca una fortificación defensiva, ubicada en lo alto de una roca (v. 5585), provista de «cretel hordé» (v. 5578) y de «uiz et de cloies» (v. 5579) que lo rodean con una única puerta de acceso (v. 5587). El castillo encierra un palacio y una torre alta que repite los mismos mecanismos de defensa: «mout bien cretelee;» (v. 5581) y «tot environ estoit hordee» (v. 5582). El aislamiento y la verticalidad del lugar garantizan la protección de sus habitantes, que temen al rey Arturo, pero se trata en realidad de un castillo prisión (vv. 5451-5452), donde noventa caballeros han sido encerrados por Creoréas, y de donde sólo se puede salir previo pago de un rescate. Durmart, reciente bacheler, libera a los prisioneros tras afrontar un combate desigual contra los caballeros de Creoréas primero y contra 
él mismo después, y consuma una aventura que caballeros emblemáticos de la Mesa Redonda como Galván, Yván, Lanzarote, Engrevain el Orgulloso, Perceval y Keu, habían intentado sin éxito. Esta confrontación entre el hijo del rey de Gales y los caballeros de la Mesa Redonda retorna en otros dos episodios de la novela diferidos en el tiempo: el torneo de Blanches Mores y la guerra de Limeri, que consagran la superioridad de Durmart sobre los caballeros artúricos.

La descripción topográfica de los castillos de Brun de Branlant y del Felón de la Garde se asemeja, a primera vista, a la de una fortaleza. Así, el castillo de Brun de Branlant es «fort et bien seant» (v. 3797), y el del Felón, erigido sobre un otero (v. 5208), está circundado por unas murallas almenadas (v. 5206). Sin embargo, sus puertas están abiertas para acoger al caballero errante: «Mesire Durmars a trovee | La maistre porte defermee» (v. 3817-3818); «Mesire Durmars tant erra $\mid$ Qu'al chastel vint, et si trova $\mid$ La grant porte desverroillie» (vv. 5223-5225). Durmart encuentra al Felón, el caballero instaurador de la mala costumbre del peaje de caminos, abolida por el héroe, sentado junto a su mujer y siete caballeros de su mesnada en un prado, escuchando a un cantor. Ambos castillos están ligados a la hospitalidad caballeresca, motivo narrativo que presenta, según Bruckner, cuatro fases: «I Welcome, II Suppertime, III Bedtime, IV Departure» ${ }^{29}$. Esta novela amplifica las fases I y II, especialmente la segunda, modelada a partir de elementos diversos según el principio de la variatio, consustancial a la escritura medieval, para evocar una atmósfera refinada, que idealiza la realidad de la nobleza contemporánea y constituye uno de los rasgos más característicos de esta novela. A la función descriptiva desempeñada por estos ágapes se une, en no pocas ocasiones, la narrativa, ya que en ellas se asocia comida y palabra, de manera que el héroe obtiene en ellas informaciones o toma decisiones que guiarán su búsqueda. El Felón de la Garde comparte la escudilla con Durmart (v. 5261), como signo de una cordialidad ${ }^{30}$ cortés que desmiente el significado de su nombre. Por otra parte, le hace saber que la reina de Irlanda le ama y da un giro a la búsqueda del protagonista, orientándola hacia la corte del rey Arturo en Glastingebiere, hasta el momento ausente en la novela.

Las dos visitas de Durmart al castillo de Brun de Branlant, ambas vespertinas, transcurren en dos estaciones distintas: finales de primavera o comienzo del verano la primera y finales de otoño o

\footnotetext{
${ }^{29}$ Cfr. Matilda Tomaryn Bruckner, «Repetition and variation in Twelfth-Century French Romance», en Nathaniel B. Smith y Joseph T. Snow (eds.), The Expansion and Transformations of Courtly Literature, Athens, University of Georgia Press, 1980, pp. 95-114, p. 100; y Madeleine Jeay, «Scènes de repas et catalogues gastronomiques dans l'écriture romanesque», en Nelly Labère (ed.), Etre à table au Moyen Âge, Madrid, Casa de Velázquez, 2010, pp. 213-225; p. 213.

${ }^{30}$ Gornemant de Goort comparte también su escudilla con Perceval en la comida de la víspera de su investidura; cfr. Chrétien de Troyes, Les romans de Chrétien de Troyes. V. Le conte du Graal (Perceval), ed. de Félix Lecoy, 2 vols., París, Honoré Champion, 1981, vv. 1557-1561.
} 
comienzo de invierno la segunda, de manera que el autor compone sus representaciones en función de la meteorología. En primavera, la luz proviene de la luna, es decir, del exterior: «La lune luit et bele et cleree» (v. 3806); el tiempo suave permite a sirvientes y escuderos reunirse en un prado al sereno para solazarse (vv. 3821-3823). Dos centinelas tocan la flauta y las campanillas en dos torres altas «Sans faillir et sens descorder» (v. 3816). La armonía de la música suaviza la rigidez de la arquitectura y transforma a los vigías en músicos. La estación fría, por el contrario, rige una estampa íntima de interior acogedor, iluminado por las altas candelas y, sobre todo, caldeado por un gran fuego en torno al que están dispuestos los asientos (vv. 9174-9179). En invierno, los sirvientes ofrecen agua caliente a los comensales para lavarse las manos antes de la comida (v. 9234). Si, en su primera estancia en el castillo, Durmart conoce por boca de su anfitrión que la dama del gavilán es la reina de Irlanda, en la segunda, tras el recorrido por los castillos y la victoria en el torneo de Blanches Mores, Brun de Branlant le hace entrega de armas nuevas, idénticas a las que había recibido de su padre el día de su investidura y llevaba al comienzo de su aventura, gesto cargado de significación ${ }^{31}$. El castillo y el ágape sellan el final de una etapa de la aventura del héroe: la adquisición de una reputación digna de su linaje y superior a la de los caballeros de la Mesa Redonda. Durmart está en disposición de acometer la gran empresa de la guerra de Limeri.

La descripción del castillo de Morois, nombre de resonancias tristanianas, está integrada en el relato, como la de la ciudad de Glastingebiere, y acompaña el desplazamiento de Durmart, que lo divisa desde lejos, se aproxima y finalmente entra. La defensa es su rasgo distintivo. El autor refiere las barreras naturales de separación, como en el Château des Moulins: «de mares et de croliere» (v. 4309), y sus elementos de protección:

\section{Sor les murs voit mainte tornele \\ Plus de set lices a passees \\ Et barbakanes bien fermees,}

\footnotetext{
${ }^{31}$ Durmart cambia tres veces de armas a lo largo de su búsqueda. En las primeras aventuras, culminadas por la prueba del gavilán, lleva las armas entregadas por su padre el día de su investidura: una loriga blanca, una cota de terciopelo bermejo con dos leopardos de oro, y un escudo pintado de sinople claro, con dos leopardos de oro en relieve. Brun de Morois le proporciona armas nuevas, completamente blancas, que utiliza en las aventuras de los castillos, es decir, durante la etapa en la que debe demostrar su valía. Reviste de nuevo armas idénticas a las del padre, ofrecidas por Brun de Branlant en señal de reconocimiento por las proezas acometidas, en los episodios de Glastingebiere, que sanciona su gloria, y en el de la guerra de Limeri. Según Michel Pastoureau, Figures et couleurs, op. cit., pp. 162-163, Ricardo Corazón de León fue el primero en utilizar el escudo de armas con tres leopardos de oro. Ver también Michel Pastoureau, L'Hermine et le Sinople. Études d'héraldique médiévale, París, Le Léopard d'Or, 1982, p. 109.
} 
Et si voit a chascune lice

Porte ferre coleïce. (vv. 4344-4348)

El recinto amurallado alberga una naturaleza generosa, que reúne los elementos del paisaje ideal: «Laens sunt les g[a]aigneries | Et li boiz et les praeries | Et li vergier et les fontaines | Qui sorgoient cleres et saines» (vv. 4317-4320), una ciudad y un «maistre chastel» (v. 4445). La belleza y la opulencia del espacio urbano se expresan mediante calificativos generales como «grant», «bele», «riche», «manans», o adverbios que intensifican tanto la cualidad («trop»y «bien») como la cantidad («mout»), pero especialmente gracias a la extensa enumeración de catorce vocablos encadenados, en la que se mezclan términos relativos a la habitación («maisons», «palais», «sales», «chambre», «loges»), con los de lugares destinados a una función, bien alimentaria como las «crotes», «votes», «celiers»y «molins», bien religiosa: «mostiers» y «chapeles» (vv. 4400-4410). La copia verborum transmite la copia rerum. La belleza se aprecia además en las calles pavimentadas ${ }^{32}$, limpias y despejadas, y en los elementos decorativos que adornan la arquitectura: las casas están «bien ovrees», las salas principales «fenestrees».

Este hermoso y sólido castillo es un castillo con trampa ${ }^{33}$, pues un enano jorobado advierte a Durmart y a su compañero Ydier de que corren el riesgo de ser decapitados si son vencidos por su señor (vv. 4509-4516), que retiene prisionera a la reina Ginebra tras haberla raptado. Sin embargo, todos los peligros se desvanecen en el jardín contiguo, donde Durmart encuentra a Brun de Morois sentado junto a la reina sobre una tela de seda y orifrés (vv. 4536-4537), a la sombra de un frondoso árbol. El vergel, «hortus conclusus»» ${ }^{34}$ cerrado por una puerta magnífica (v. 4527), representa el espacio privado e íntimo donde se unen armoniosamente la naturaleza y el artificio para satisfacer los deseos amorosos de Brun, convertido en un nuevo Lanzarote. Su importancia relega a un segundo plano al resto del castillo, pues en la landa que alberga se libra el combate entre el héroe y el raptor de la reina. La victoria de Durmart con la consiguiente liberación de Ginebra establece el primer lazo de unión entre el hijo del rey de Gales y el rey Arturo.

${ }^{32}$ Las calles de la ciudad de Chef d'Oire en Partonopeu de Blois. A French Romance of the Twelfth Century, ed. de Joseph Gildea, 2 vols., Villanova (Penn.), Villanova University Press, 1967-1970, vv. 825-830, también están pavimentadas y limpias.

${ }^{33}$ Francis Dubost, Aspects fantastiques de la littéraure narrative médiévale (XII $-X I I I^{e}$ siècles). L'Autre, l'Ailleurs, l'Autrefois, 2 vols., París, Honoré Champion, 1991, p. 370.

${ }^{34}$ A propósito del motivo del "hortus conclusus", ver Marie Françoise Notz, «Hortus conclusus», en Mélanges de littérature du Moyen Âge au XXe siècle offerts à Jeanne Lods par ses collèges, ses élèves, París, Collection de l'École normale supérieure de jeunes filles, 1978, pp. 459-473, y J.-C. Bibolet, «Jardins et vergers dans l'œuvre de Chrétien de Troyes», Senefiance. Vergers et jardins dans l'univers médiéval, 28 (1990), pp. 34-40. 
El reconocimiento que Brun de Morois debe a Durmart por su victoria en la liza se manifiesta en el ceremonial de la cena que como anfitrión ofrece a su huésped. Le distingue no sólo dejando que sea el primero en lavarse las manos (vv. 5000-5001), sino también sentándolo a su lado en la mesa más elevada (vv. 5002-5004), gesto propio de señores o reyes ${ }^{35}$.

El Château aux Dix Pucelles es un motivo frecuente en las novelas artúricas, cuyos elementos constitutivos y significación evolucionan y se transforman ${ }^{36}$, pero que se define por la suspensión del tiempo, fenómeno habitual en los espacios del Otro Mundo, y por la hiperfeminidad. En Durmart, este motivo ha perdido su atributo feérico y maravilloso para convertirse en una especie de lugar utópico antes de tiempo, a la manera de la abadía de Thélème de Rabelais. $\mathrm{Su}$ topografía repite algunos elementos recurrentes en los castillos anteriores. Se erige en medio de un paisaje bello y feraz de viñas y de prados floridos (v. 6192); está bien defendido por zanjas y murallas almenadas (vv. 6193-6195), y protegido por un río profundo y un inmenso bosque (vv. 6189-6190); los edificios están, finalmente, cubiertos de plomo (vv. 6196-6198). Pero el rasgo más específico lo constituyen sus habitantes y su modo de vida. Residen en él diez jóvenes doncellas bellas y agradables que han reunido todas sus tierras en una comunidad en la que la propiedad privada no existe, ya que todos los bienes son colectivos: «Tote lor terre ont mise ensemble | Dont eles ont, si com moi semble, | Plus de trente et neuf cent livrees» (vv. 6117-6119). El nombre del lugar no responde a la segregación sexual que caracteriza al castillo en las novelas artúricas; más bien al contrario, las doncellas conviven armoniosamente con diez caballeros de gran prez:

Beaz et cortois et bien jolis.

Trestot sont si chevalerous

[Mains] bons chevaliers est mains prous;

Tot se sunt a un acort mis,

Si mainent ensemble todis (vv. 6122-6126)

\footnotetext{
${ }^{35}$ Monique Closson, «Us et coutumes de la table $\mathrm{du} \mathrm{XI} \mathrm{I}^{\mathrm{e}}$ siècle au Xv ${ }^{\mathrm{e}}$ siècle à travers les miniatures», en Denis Menjot (ed.), Actes du Colloque de Nice (15-17 octobre 1982). T. 2. Cuisine, manières de table, régimes alimentaires, Niza, Publications de la Faculté des Lettres et Sciences Humaines de Nice. Les Belles Lettres, 1984, pp. 21-32; p. 30, señala, a través del análisis de miniaturas de los siglos XIII al xv, que casi todas las mesas señoriales, burguesas y eclesiásticas estaban montadas sobre caballetes, y en ocasiones sobre un estrado, "pour permettre aux seigneurs de dominer ceux qui les servent, ou leur demandent audience».

${ }^{36}$ Emmanuèle Baumgartner, «Le Château des Pucelles: variations sur un motif arthurien», en Denis Hüe y Christine Ferlampin-Acher (eds.), Le Monde et l'Autre Monde. Actes $d u$ colloque arthurien de Rennes des 8 et 9 mars 2001, Orléans, Paradigme, 2002, pp. 37-49, revisa la evolución de este motivo artúrico desde la Historia regum Britanniae de Geoffrey de Monmouth hasta La Suite du Roman de Merlin.
} 
A diferencia de lo que sucede en las sociedades utópicas, igualitarias por definición, la de este castillo presenta una estructura jerarquizada: los hombres están bajo la autoridad de Geogenant y las mujeres de Dyonise, su soberana. Sin embargo, son las cualidades individuales, belleza, arrojo y bondad, las que establecen el rango (vv. 6163-6166). El Château aux Dix Pucelles de Durmart representa, más bien, el paradigma de la caballería cortés. La vida de los que en él habitan ilustra el credo caballeresco practicado en la novela, que combina armoniosamente el movimiento necesario para buscar la aventura, afrontar combates o participar en guerras y torneos, y el reposo para celebrar fiestas y solazarse (vv. 6136-6160). Además, las damas y los caballeros conversan sobre amor y caballería en un prado, bajo un emparrado de racimos (vv. 6221-6227), a la manera de las cortes de amor, privilegiando el espacio exterior sobre el interior, como sucede en otros muchos lugares de la novela. Microcosmos de la perfección caballeresca y cortés, funciona como espejo que confirma la trayectoria del héroe en la antesala del episodio del torneo de Blanches Mores.

El narrador no escatima detalles para describir el festín celebrado en el Château aux Dix Pucelles, tanto en lo que concierne al menú servido como al ceremonial de mesa. La llegada de Durmart al castillo un viernes condiciona la elección de platos, ya que ese día la Iglesia exige la abstinencia de carne, es decir, la vigilia ${ }^{37}$, razón por la cual la carne de la tríada alimenticia caballeresca -pan, vino y carne $^{38}$ - es sustituida por pescado. Sin embargo, es el ágape más copioso y exquisito, en consonancia con el lugar y sus moradores. El menú acumula una lista de seis pescados diferentes de mar y de agua dulce: lampreas, salmones, lubinas, mújoles, esturiones y lucios, acompañados por una salsa caliente, muy refinada, que mezcla

${ }^{37}$ La abstinencia de carne se extiende al sábado, también «jour maigre». Así pues, en Erec et Enide los esposos comen pescado (lucios, percas, salmones y truchas) y fruta un sábado por la noche en la corte del rey Arturo; ver Chrétien de Troyes, Les romans de Chrétien de Troyes. I. Erec et Enide, ed. de Mario Roques, París, Honoré Champion, 1978, vv. 4237-4240.

${ }^{38}$ Anita Guerreau-Jalabert, «Aliments symboliques et symbolique de la table dans les romans arthuriens (XII ${ }^{\mathrm{e}}$ et XIII ${ }^{\mathrm{e}}$ siècles)», Annales ESC, 47/3 (1992), pp. 561-594, opone el régimen caballeresco (pan-vino-carne) al régimen eremítico (pan-agua-vegetales); se puede leer también Anita Guerreau-Jalabert, «Les nourritures comme figures symboliques dans les romans arthuriens», en Martin Aurell, Olivier Dumoulin y Françoise Thelamon (eds.), La sociabilité à table. Commensalité et convivialité à travers les âges. Actes du colloque de Rouen avec la participation de Jacques Le Goff, 14-17 novembre 1990, Rouen, Publications de l'Université de Rouen $\mathrm{n}^{\circ} 178,1992$, pp. 35-40. Jacques Voisenet, «Le banquet chrétien au haut Moyen Âge ( $\mathrm{V}^{\mathrm{e}}-\mathrm{XI}{ }^{\mathrm{e}} \mathrm{s}$.): un plaisir encadré», Senefiance. Banquets et Manières de Table au Moyen Âge, 38 (1996), pp. 545-559; p. 546, distingue tres tipos de banquete: profano, divino y cristiano. El primero se define por el régimen alimenticio formado por la tríada pan-carnevino. Este modelo sintetiza, según Micheline Combarieu du Grès, «Bonnes et mauvaises manières de table dans la Chanson de Guillaume et Aliscans», Senefiance. Banquets et Manières de Table au Moyen Âge, 38 (1996), pp. 283-301; pp. 297-298, dos tradiciones alimentarias y culturales: la de la Antigüedad greco-latina, fundada sobre la tríada pan-vino-aceite, y la de los Germanos y Celtas, en la que la carne, el vino y otras bebidas alcohólicas desempeñan un papel de primer orden. 
especias muy apreciadas, como la pimienta, el clavo y la canela. Todo ello regado con excelentes vinos claretes y generosos (vv. 6338-6343). No podían faltar los electuarios y las especias digestivas como el jengibre ${ }^{39}$ para después de la cena: «Laituaires aporter font | D'espices et de gingebras;» (vv. 6356-6357). Los anfitriones sientan a Durmart junto a ellos en la mesa más alta y es el propio Geogenant el encargado del servicio. La música que acompaña cada plato constituye otro signo de cortesía y de distinción social. Ausente de las comidas que el héroe realiza en el transcurso de su itinerario, es privativa de los lugares más refinados de la novela: el Château aux Dix Pucelles, donde una doncella toca lais al arpa y (vv. 1031-1033), y las cortes de los reyes Jozefent y Arturo. La puesta en escena del banquete es todavía muy modesta, comparada con las pantomimas y entremeses ${ }^{40}$, que recrean magníficos espectáculos en los banquetes regios del siglo XV.

\section{CONCLUSIÓN}

Durmart exhibe una voluntad desmitificadora con respecto a la tradición de la novela artúrica. La corte del rey Arturo deja de ser el epicentro de la novela y sus funciones habituales -investidura, reconocimiento, bodas, coronación y entrada triunfal- se distribuyen entre la Blanche Cité, origen y fin de la aventura del héroe, y Limeri. Sus caballeros más apreciados -Galván, Lanzarote, Perceval, Keu...- son vencidos por Durmart, «bacheler» recientemente investido, en las tres ocasiones en las que la aventura los enfrenta -liberación de los prisioneros del castillo de Roche Brune, torneo de Blanches Mores y guerra contra el rey Nogant-. Los motivos artúricos que la novela incorpora en su intriga -"Arbre aux chandelles", "Siège Périlleux" y "Château des Pucelles"-aparecen banalizados y desvirtuados de su significación canónica.

La descripción de las numerosas ciudades y castillos que pueblan la novela mantiene los estereotipos habituales de verticalidad y solidez, para subrayar su independencia y soberanía, pero atenúa el aislamiento hasta hacerlo desaparecer. Las únicas excepciones son

\footnotetext{
${ }^{39}$ Sobre las propiedades digestivas del jengibre, ver Charles Foulon, «Les quatre repas de Perceval», en Jacques de Caluwé (ed.), Mélanges de philologie et de littérature romanes offerts à Jeanne Wathelet-Willem, Lieja, Association des romanistes de l'Université de Liège, 1978, pp. 165-174; p. 171.

${ }^{40}$ Danielle Queruel, «Des entremets aux intermèdes dans les banquets bourguignons», Senefiance. Banquets et Manières de Table au Moyen Âge, 38 (1996), pp. 143-157, traza la evolución del significado de la palabra entremes entre los siglos XII y XV. El primero, en concordancia con su etimología, es: «ce qui est servi ou montré entre les plats». En el Roman de la Violette de Gerbert de Montreuil, esta palabra es utilizada en el sentido de «conversation coupant le déroulement d'un repas et distrayant les convives». En los siglos XIV y XV, el término entremes fue empleado tanto para designar preparaciones culinarias concretas, como para las decoraciones de mesa más o menos elaboradas y los divertimentos ofrecidos en el transcurso de las comidas.
} 
la ciudad de Limeri y los castillos de Moulins y de Roche Brune, espacios que conservan la condición de fortaleza inexpugnable. De esa manera, su liberación exalta la proeza de Durmart. Las demás ciudades y castillos se presentan como lugares abiertos, de acogida, y propician la sociabilidad y el esparcimiento. La música suaviza los rasgos defensivos de los castillos de Brun de Branlant y del Felón de la Garde; el vergel de Morois transforma la prisión de Ginebra en un lugar de recreo, pero sobre todo los banquetes, acompañados de su refinado ceremonial, privilegian la convivialidad y la conversación, en ocasiones indispensable para el progreso de la aventura del héroe. La intriga se articula a través de castillos y banquetes que desempeñan una función complementaria en la novela. Durmart expresa su deseo de ser investido caballero y de cambiar de vida en el transcurso del banquete ofrecido por el rey Jozefent, y emprende la búsqueda de la reina de Irlanda al final del celebrado en Pentecostés en la Blanche Cité. Durante la cena de su primera estancia en el castillo de Brun de Branlant, el héroe se entera de la identidad de la reina de Irlanda, que ya había conocido de incógnito. El Felón de la Garde le informa en la comida de que la reina le ama y hace girar su aventura hacia Glastingebiere y el universo de la Mesa Redonda. Durmart libera a noventa prisioneros en el castillo de Roche Brune, y en el de Dix Pucelles Geogenant le dirige hacia el torneo de Blanches Mores, para medirse con los caballeros artúricos. Brun de Branlant le provee, en la segunda estancia en su castillo, de armas nuevas, idénticas a las recibidas en su investidura, y de las que es merecedor por las proezas realizadas. Tres ciudades sirven de marco a la apoteosis de Durmart: Glastingebiere, que confirma su valía; Limeri, donde se libra la guerra para la liberación de la reina de Irlanda, donde contrae matrimonio y es coronado rey, y Roma, escenario de la cruzada triunfal.

Estas ciudades abiertas constituyen centros en los que se congrega la muchedumbre necesaria para la celebración de grandes ceremonias: cortes plenarias, investidura caballeresca, bodas, coronación, entrada triunfal, pero también juegos guerreros -la prueba del gavilán, el torneo- e incluso la guerra de Limeri, teatralizada y convertida en espectáculo. Los castillos, por su parte, sirven de marco para la fiesta privada, cuya versión más frecuente es el banquete. Durmart privilegia la fiesta, a la vez que proclama el triunfo de los caballeros nuevos, como Procidas y el propio héroe, vencedores de la guerra de Limeri. 
$\cos$

\title{
EL ESPACIO CONSTRUIDO, EL BANQUETE Y LA FIESTA EN DURMART LE GALOIS
}

RESUMEN: Durmart le Galois no es una novela artúrica convencional. Los caballeros de la Tabla Redonda son relegados a un segundo plano frente al protagonismo que cobra el héroe epónimo. Su estructura carece de una etapa de crisis personal o social del héroe, de forma que la aventura constituye un itinerario cuyas etapas se despliegan a través de una vasta geografía. Los castillos y ciudades se imponen sobre otros espacios salvajes, como el bosque, más frecuentes en otras obras caballerescas. La descripción de estos lugares construidos parte de los cánones establecidos por la tradición literaria, pero se aleja después y muestra un espacio amable, abierto a la sociabilidad y al entretenimiento. El ambiente festivo inunda la novela y encuentra su culminación en el banquete, con sus rituales y su protocolo. En torno a la mesa, los comensales intercambian conversaciones que marcarán el progreso de la intriga.

Palabras clave: espacio, sociabilidad, banquete, fiesta.

\section{BUILT SPACES, BANQUETS AND PARTIES IN DURMART LE GALOIS}

\begin{abstract}
Durmart le Galois is not a conventional Arthurian novel. The knights of the Round Table are pushed into the background, while relevance is given to the eponymous hero. Its structure lacks a stage of personal or social crisis of the hero, so, adventure covers an itinerary whose stages are displayed throughout a vast geography. Castles and cities replace other wild spaces, such as the forest, which are more frequent in other chivalric works. The description of these built-up spaces starts from the pre-established literary canons, but later it moves away from conventions, and it depicts a gentle space, which is open to sociability and entertainment. A merry atmosphere floods the novel, and it reaches its climax in the banquet, with its rituals and protocol. Around the table, guests exchange conversations, which will influence the unfolding of the plot.
\end{abstract}

KEYWORDS: space, sociability, banquet, party. 